\title{
Metformin and CVD prevention
}

\author{
Gerti Tashko* \\ Endocrinologist, Diabetes Specialist, Hypertension Specialist, USA
}

Submission: August 1, 2017; Published: August 14, 2017

*Corresponding author: Gerti Tashko, Endocrinologist, Diabetes Specialist, Hypertension Specialist, USA, Email: gtash001@gmail.com

Abbreviations: ARIC: Atherosclerosis Risk in Communities; ADA: American Diabetes Association; AACE: American Association of Clinical Endocrinologists; IDF: International Diabetes Federation; CVD: Cardiovascular Disease; DPPOS: Diabetes Prevention Program Outcomes Study

\section{Introduction}

Diabetes type 2 prevalence is high, about $10 \%$ of US population. Prediabetes is even more common, about 3 times higher than diabetes, approaching $30 \%$ of population. Diabetes is defined by confirmed $\mathrm{A} 1 \mathrm{c} \geq 6.5 \%$, while prediabetes is any A1c between 5.7 $6.5 \%$. ADA guidelines conceptualize prediabetes as an entity that places individuals at higher risk of progression to full diabetes. However recent studies have shown that prediabetes alone, in the absence of diabetes, can still increase the risk of clinical complications. For example the rate of all-cause hospitalization was $30 \%$ higher in prediabetes than individuals with A1c $<5.7 \%$ in the Atherosclerosis Risk in Communities (ARIC) study. About 13,000 participants were followed for 11 years [1].

Major international guidelines, such as American Diabetes Association (ADA), American Association of Clinical Endocrinologists (AACE), European Association for the Study of Diabetes (EASD) and International Diabetes Federation (IDF) appropriately recommend lifestyle modifications as the ultimate first line intervention to prevent diabetes progression, and when appropriate to bring it under control A1c $<7.0 \%$. Such interventions would be lower carbohydrate diet, weight loss and increased physical activity. If lifestyle changes fail or are not sufficient then guidelines generally agree that the initial pharmacological agent should be metformin.

Metformin, FDA approved in 1994, is a relatively potent antidiabetic medication. Alone it can lower A1c by up to $1.5 \%$. It targets one of the root causes of type 2 diabetes; insulin resistance at the liver site, leading to decreased glycogenolysis, gluconeogenesis and eventually to improved hyperglycemia. Adverse events are relatively rare; in short term it could cause diarrhea and GI upset possible B12 deficiency after few years of chronic use, and in extreme cases lactic acidosis. Lactic acidosis occurs in $<10$ out of 100,000 metformin users [2], and frequently seen in an intensive care "perfect storm" clinical setting such as in acute renal injury, sepsis, hypothermia, hypotension or decompensated cardiac or hepatic failure.

\section{Cardiovascular Prevention}

The ultimate goal of diabetes therapy is prevention of complications; microvascular and macrovascular. Cardiovascular illness is the number one cause of death in persons with diabetes. Retarding cardiovascular disease (CVD) would thus be the most rational approach to initial diabetic management. Recent studies published in 2017 provide more clues to importance of early metformin use in individuals with prediabetes and type 2 diabetes. ADA 2017 standards recommend considering metformin, more than any other antidiabetic agent, in persons with prediabetes and worsening A1c, as it has shown to delay the onset of diabetes by a few years [3]. Data from Diabetes Prevention Program Outcomes Study (DPPOS), published in Circulation May 2017 revealed that prediabetic men treated with metformin had significantly lower coronary calcium score than non-users during the 14 year follow up. Such benefits were not seen in women, which could be from their lower inherited baseline CVD [4]. Elevated coronary calcium score has been established to be an independent risk factor for cardiovascular events. Another study published in Diabetes Care March 2017 showed that aggressive A1c reduction with metformin in early diabetes lead to reduced cardiovascular outcomes, including mortality. Such impressive results were seen relatively quickly, within 3 years of metformin initiation. About 25,000 patient data were followed and analyzed [5].

A meta-analysis published in the Journal of Hypertension January 2017 uncovers that Metformin, compared to placebo, can lower systolic blood pressure by $5 \mathrm{mmHg}$ in subjects with prediabetes. This is significant as any degree of blood pressure elevation adds an incremental risk toward atherosclerosis. Results 
are in accordance with the notion of insulin resistance being at the center of metabolic syndrome; manifestations of which are both increased glycemia and blood pressure. About 4,000 subjects from 28 studies were included in the meta-analysis [6].

\section{Conclusion}

Recent literature suggests that early metformin use could help reduce CVD progression and outcomes in patients with prediabetes and type 2 diabetes beyond glycemic control. It is important to discuss this information with individuals who are in the prediabetic or early diabetic stages of the disease, A1c 5.7-7.0\%. Benefits should be weighed against metformin adverse effects, polypharmacy, life expectancy and comorbidities, particularly in the setting of cardiac, renal or hepatic pathology. Individualized patient discussion and clinical decision would be pivotal to proper medical care.

\section{References}

1. Andrea LC Schneider, Rita R Kalyani, Sherita Golden, Sally C Stearns, Lisa Wruck, et al. (2016) Diabetes and Prediabetes and Risk of Hospitalization: The Atherosclerosis Risk in Communities (ARIC) Study. Diabetes Care 39: 772-779.
2. DeFronzo R, Fleming GA, Chen K, Bicsak TA (2016) Metforminassociated lactic acidosis: Current perspectives on causes and risk. Metabolism 65(2): 20-29.

3. Sherwin RS, Anderson RM, Buse JB, Chin MH, Eddy D, Fradkin J, et al. (2004) Prevention or Delay of Type 2 Diabetes. Diabetes Care 27(Suppl 1): S47-S54.

4. Goldberg RB, Aroda VR, Bluemke DA, Barrett Connor E, Budoff M, et al. (2017) Effect of Long-term Metformin and Lifestyle in the Diabetes Prevention Program and its Outcome Study on Coronary Artery Calcium. Circulation 136(1): 52-64.

5. Svensson E, Baggesen LM, Johnsen SP, Pedersen L, Nørrelund H, et al. (2017) Early Glycemic Control and Magnitude of HbA1c Reduction Predict Cardiovascular Events and Mortality: Population-Based Cohort Study of 24,752 Metformin Initiators. Diabetes Care 40(6): 800-880.

6. Zhou L, Liu H, Wen X, Peng Y, Tian Y, et al. (2017) Effects of metformin on blood pressure in nondiabetic patients: a meta-analysis of randomized controlled trials. J Hypertens 35(1): 18-26.

Your next submission with Juniper Publishers will reach you the below assets

- Quality Editorial service

- Swift Peer Review

- Reprints availability

- E-prints Service

- Manuscript Podcast for convenient understanding

- Global attainment for your research

- Manuscript accessibility in different formats ( Pdf, E-pub, Full Text, Audio)

- Unceasing customer service

Track the below URL for one-step submission https://juniperpublishers.com/online-submission.php 